\title{
Perceptions of Community Benefits from Two Wild and Scenic Rivers
}

\author{
Jordan W. Smith · Roger L. Moore
}

Received: 11 September 2009/ Accepted: 25 March 2011/Published online: 11 April 2011

(C) Springer Science+Business Media, LLC 2011

\begin{abstract}
Wild and Scenic Rivers provide a host of psychological, social, ecological, and economic benefits to local communities. In this study, we use data collected from recreational users of two Wild and Scenic Rivers to examine perceptions of the benefits provided by the rivers to local communities. Our purposes are (1) to determine if similar perceptions of community benefits exist across the two rivers, (2) to determine if individuals' proximity to the rivers are related to the benefits they perceive, (3) to determine if individuals' prior recreation experience on the river is related to variations in perceived benefits, (4) to determine if users' sociodemographic characteristics are related to perceived community benefits, and (5) to determine if the influence of these characteristics on perceived community benefits is similar across the two resource areas. Perceived benefits were found to be analogous across both rivers as individuals consistently ranked ecological/ affective benefits as well as tangible benefits similarly. Recreationists living further from the river ranked ecological and affective benefits as significantly less important than those individuals living closer to the river. Women perceived the community benefits produced by the resource areas to be significantly more important when compared to men. Significant relationships were also found between perceived benefits and recreationists' previous use of the river, their age, and their level of education. With the exception of resource proximity and prior use history, the effects of user characteristics on perceived community benefits were not statistically different across the two
\end{abstract}

J. W. Smith $(\square)$. R. L. Moore

College of Natural Resources, North Carolina State University,

Box 8004, Biltmore Hall (NCSU), Raleigh, NC 27695-8004,

USA

e-mail: jwsmit12@ncsu.edu rivers. These findings imply similar patterns of perceived community benefits exist across distinct resource areas and that the relationships between user characteristics and perceived benefits are also similar across the study rivers.

Keywords Wild and scenic rivers - Community benefits . Local/non-local · Outcomes-focused management

\section{Introduction}

Wild and Scenic Rivers, like most wildland recreation areas, provide a diverse array of psychological, social, ecological, and economic benefits to recreationists (Driver and others 1991). Communities located near Wild and Scenic Rivers often benefit in a variety of ways as well. Wild and Scenic River designation, for example, can impact local economies as more recreationists visit designated rivers because they either offer particularly desirable recreation experiences or because designation increases public awareness and visibility (Palmer 1993). Concurrently, designation may also result in unwanted impacts such as higher levels of development and greater tax rates (Davenport and Anderson 2005; Moore and Siderelis 2003a, b). Despite the many impacts that a Wild and Scenic River can have on local communities, relatively little empirical research on the subject has been conducted (Keith and others 2008). In this study, we begin to address this issue by specifically examining recreationists' perceptions of how two Wild and Scenic Rivers in the eastern United States benefit local communities.

Recreation research has only recently begun to seriously address the benefits of wildland recreation resources from the perspective of local communities (e.g., Anderson and others 2008a; Leahy 2005; Stein and others 1999). This 
growing body of literature has attempted to shift the focus of Outcomes Focused Management (OFM), an established and widely adopted approach to recreation resource management, from providing opportunities solely for individual benefits to providing opportunities for local community benefits as well. Gauging perception of community benefits is long overdue given the increased importance for collaborative management and stakeholder involvement in recreation and public lands management (Daniels and Cheng 2004). Research focused on community benefits can also "give policy makers, administrators, landscape planners, and managers a better understanding of how their actions and decisions...impact society" (Stein and others 1999, p. 2).

In this study, we examine resource users' perceptions of local community benefits across two distinct Wild and Scenic Rivers in the eastern United States-the West Branch of the Farmington River, an urban proximate river used primarily for fishing, and the Chattooga River, a more remote river used primarily for whitewater recreation. We assume the benefits provided by Wild and Scenic Rivers to local communities are not deterministic. Rather, like other wildland recreation resources, unique benefits are produced by distinct combinations of settings, activities, and management systems (c.f., Driver 2008a; Moore and Driver 2005). By collecting and analyzing data from two rivers which differ dramatically in their physical setting and in the types of activities they support, we are able to explore whether recreationists believe the rivers produce similar benefits for local communities despite such variable factors. Given this, the first purpose of this study is to determine if recreationists on two distinct Wild and Scenic Rivers believe the resource produces similar benefits for local communities.

Individuals' perceptions of how local communities benefit from being located near a Wild and Scenic River could also differ according to whether those individuals are recreationists who travel relatively long distances to reach the river or if they are individuals who live in a community proximate the resource. Individuals who live near the river could have significantly different perceptions of how the river benefits their community than individuals who travel there just for recreation. An individual's knowledge of the river's impacts (both positive and negative) on the community could also influence their perceptions about community benefits. Acknowledging this, the second purpose of this study is to determine if, and how, individuals' proximity to the resource area is related to their perceptions of community benefits.

As the research on community benefits is relatively new, we also explore the relationship between basic user characteristics, such as previous use experience and basic sociodemographic characteristics, and perceived community benefits. Specifically, the third and fourth purposes of this study are to determine if users' characteristics, specifically their patterns of use history and their socio-demographic characteristics, are related to the perceived importance of different community benefits. The fifth and final purpose of this study is to determine if the relationships between users' characteristics and their perceptions of community benefits are similar across the two Wild and Scenic Rivers.

In the following sections, we outline the origins and fundamentals of OFM and how understanding perceptions of community benefits is integral to its engagement as a management framework. We also outline the previous literature on community benefits, and the related literature concerning resource proximity and recreationists' perceptions of community benefits.

\section{Related Literature}

\section{Outcomes-Focused Management}

Within the recreation literature, benefits have typically been described as either (1) advantageous changes or improvements in a condition to individuals, groups, communities, society, or other elements of the natural world, (2) the prevention of an unwanted condition, or (3) the realization of a satisfying recreation experience (Driver and others 1991). Benefits have long been important in recreation scholarship and management because they represent the positive outcomes available to recreationists and local communities from the management and use of recreation and related amenity resources and programs (Driver 2008a). The provision of benefits to society at large is also explicitly stated in the mandates of most federal land management agencies (e.g., USDA Forest Service (National Forest Management Act 1976), Bureau of Land Management (Federal Land Policy and Management Act 1976), National Park Service (National Park Service Organic Act 1916), Fish and Wildlife Service (National Wildlife Refuge System Improvement Act 1997), and the U.S. Army Corps of Engineers (Federal Water Project Recreation Act 1965)).

If federal land management agencies are mandated to provide benefits to recreationists, local communities, and society, these agencies must be able to identify beneficial outcomes and understand variations in the benefits desired. Given this need, several of the federal land management agencies noted above, in conjunction with social scientists, have developed management frameworks that explicitly guide management actions to maximize beneficial outcomes (c.f., Bruns and others 1994). Specifically, the Recreation Opportunity Spectrum (ROS) was developed and implemented widely in the early 1980s as a managerial framework that focused management actions on providing 
opportunities for a range of possible experiences within a resource area (Moore and Driver 2005). Managers and scholars soon expanded upon the framework of managing for a variety of potential experiences, or experienced-focused management (EFM). Outcomes-focused management (OFM) emerged in the early 1990s as the next evolutionary step in managing for desired outcomes. OFM has since generated considerable academic interest in literatures concerned with the provision and management of wildland recreation opportunities (e.g., Stein and Anderson 2002; Stein and others 1999; Stein and Lee 1995).

OFM requires that "recreation and related amenity professionals understand how to capture the positive and avoid the negative effects of their management" (Driver 2008 b, p 23). This requires an understanding of the myriad outcomes of current and potential management actions. Management actions affect not only recreationists, but local communities as well. If federal land management agencies are to focus on outcomes, they must also acknowledge the perceived effects of wildland recreation resources and their management on local communities.

\section{Community Benefits}

The benefits provided to local communities from wildland recreation areas and their management have been explored through a variety of academic disciplines including human ecology (e.g., Eder 2005), economics (e.g., Hjerpe and Kim 2007; Moore and Siderelis 2003a, b), rural sociology (e.g., Cramer and others 1993), social-psychology (e.g., PerezVerdin and others 2004), and wildlife management (e.g., Lemelin 2009). As the resource/community connection can be somewhat inherent or implied in a variety of research, the related literature can quickly become broad and tangential. We focus here specifically on studies that have addressed individual's perceptions of the benefits local communities derive from wildland recreation resources.

Perceptions of community benefits are often classified into three broad categories: perceived ecological benefits, perceived economic benefits, and perceived social benefits. Several studies have used this broad typology to examine variations in how individuals believe managed resource areas benefit local communities. For example, Stein and others (1999) examined the perceptions of stakeholders living near two state parks in Minnesota. The authors found individuals predominantly thought the most important benefits were ecological (e.g., the park benefits the community by providing a place to preserve/conserve various natural and unique ecosystems). Results also showed that stakeholders believed the state parks provided significant economic benefits to local communities. Stakeholders also perceived social benefits as important outcomes of resource availability and management, although the social benefits were not as strong or consistent as either the ecological or economic benefits.

Several analyses of qualitative data have found residents living near managed resource areas tend to classify community benefits as ecological, economic, or social. In a study of individual stakeholders' perceptions of their community's relationship with a National Scenic River in Nebraska, Davenport and Anderson (2005) found the river produced social benefits, such as shaping a distinct community identity, and economic benefits through its integral role in the local agriculture, timber, and tourism industries. In a methodologically similar study of stakeholders living in an Illinois watershed managed by the U.S. Army Corps of Engineers, Leahy (2005) found community benefits were frequently described as being personal, social, or economic. According to stakeholders, the social community benefits revolved around community recreation opportunities, building a sense of community, and enabling the development of community infrastructure. Similarly the economic benefits provided by the watershed and its management revolved around increases in industry, tourism, and residential development.

The most recent research on perceived community benefits reinforces the distinction between ecological, economic, and social benefits. For example, results from a questionnaire administered to residents in the same Illinois watershed noted above revealed local residents believed the most important community benefits produced by the watershed were economic (Anderson and others 2008a). Benefits such as increased job opportunities or increased tourism were consistently ranked highly. Social and ecological benefits were also important, however, less so than economic benefits. Similar results were found in a study of residents near Voyageurs National Park in Minnesota (Anderson and others 2008a).

All these results suggest communities perceive the outcomes of wildland recreation adjacency and management in a variety of different ways; however, certain patterns do emerge. Perceived benefits tend to revolve around communities' environmental quality, their quality of life, and in nearly every case, their economy. The previous literature also shows a strong mix of both highly tangible benefits, such as increased tourism revenue, and intangible or affective benefits such as an increased sense of community and higher perceived quality of life.

One assumption of OFM is that benefits can accrue to local communities, and even to society at large, through the provision of high-quality settings that enable individuals to achieve desired recreation experiences. In short, community-level benefits are coupled with individual-level benefits. As a result, an understanding of how perceived benefits vary depending upon individuals' relationship with the resource is warranted. We focus next on three potential 
source of variation: individuals' proximity to the resource, their patterns of use history, and their socio-demographic characteristics.

\section{Resource Proximity}

Previous research on the connection between wildland recreation areas and their surrounding communities has shown a perceived increase in quality of life for those individuals who live more proximate the resource (Allen 1991; Campbell 1981; Harper and others 1997; Leahy 2005; Marans and Mohai 1991; Stein and others 1999). Previous findings have also shown more-proximate residents often value the resource for significantly different reasons than individuals living further away. Recreationists who live closer to the resource have been found to have significantly different motivations for using it when compared to recreationist who liver further away (Anderson and others 2008b). It follows that more-proximate users could hold significantly different perceptions of how the resource actually benefits their communities. The OFM framework recognizes that an individuals' connection to the resource (i.e., if they live proximate the resource, or if they are a user or a non-user) is related to how they perceive the setting itself and its management (Driver 2008b). The outcomes of management decisions likely affect local residents in distinctly different ways than users not as closely related to the resource area. Given this, there is a need to examine whether users' proximity to the resource affects their perceptions of the benefits that it provides.

\section{Differences Relative to Use History}

Recreationists' use history, their patterns of setting visitation, is related to place attachment (Hammitt and others 2004), perceptions toward resource conflict (White and others 2008), and perceptions toward crowding (Graefe and Moore 1992). While no studies have explicitly linked use history with the perceived importance of community benefits, it is plausible recreationists who engage in frequent use of the resource could become more knowledgeable about how the resource and its management impact local communities. Therefore, recreationists with different patterns of use history could hold different perceptions of how the resource benefits those communities.

\section{Differences Relative to Socio-demographic \\ Characteristics}

Perceptions of community benefits could also vary relative to individual resource users' socio-demographic characteristics. Most of the literature available to generate theoretical propositions regarding benefits produced by managed resource areas revolve around environmental attitudes. A paucity of previous research has specifically addressed individuals' perceptions of other types of community benefits (such as economic development or social benefits) generated by managed resource areas. Regarding differences in the perceptions of ecological benefits produced by managed resource areas, previous literatures have suggested that women both hold stronger pro-environmental worldviews and are more willing to support conservation measures (Hunter and others 2004; Zelezny and others 2000). This could suggest that women are more likely to perceive the ecological benefits produced through the availability and management of Wild and Scenic Rivers. The theoretical argument often associated with gendered differences regarding perceptions of wildland settings and environmental issues contends that socialization patterns, cultural norms, and women's historical role as caregivers and nurtures, lead them placing greater value on social health and welfare issues.

Previous research also suggests environmental attitudes are negatively associated with age (Dunlap and others 2000). Given this general pattern, younger individuals could be more likely to perceive the ecological benefits produced by managed resource areas. In a similar vein, pro-environmental attitudes and behaviors are often positively associated with individuals' education levels (Dunlap and others 2000) which could suggest more educated river users are more likely to believe the presence and management of Wild and Scenic Rivers produces desired ecological benefits to surrounding communities. Given the paucity of research focusing on specific types of benefits produced by managed resource areas, there is a need to more explicitly and quantitatively differentiate specific types of benefits and gain an understanding of how perceptions of them vary across resource users.

In sum, this research contributes to the scientific understanding of the connections between wildland recreation areas and local communities by specifically assessing the perceived benefits accrued to local communities through the presence and management of Wild and Scenic Rivers. It will also strengthen the scientific grounding of OFM. To make both these contributions, we specifically test five distinct hypotheses, each emerging from the literature noted above.

$\mathrm{H}_{1}$ : There will not be significant differences in perceived benefits across the two rivers. In other words, those individuals who use the Farmington River are likely to perceive the same community benefits as those individuals who use the Chattooga River.

$\mathrm{H}_{2}$ : Resource users' proximity to the river will not be significantly related to their perceptions of how the resource benefits local communities. 
$\mathrm{H}_{3}$ : Resource users' prior experience (use history) with the site will not be significantly related to their perceptions of how the resource benefits local communities.

$\mathrm{H}_{4}$ : There will be no significant relationship between individuals' perceptions of community benefits based upon their socio-demographic characteristics.

$\mathrm{H}_{5}$ : There will be no significant differences in the effects of resource proximity, use history, and socio-demographic characteristics on perceptions of community benefits across the two study rivers.

\section{Methods}

Data for this analysis come from two distinct studies of river visitors along two Wild and Scenic Rivers. The samples are comprised of river recreationists, some of whom are local residents and others whom are not. The first study was completed in 2001 along the West Branch of the Farmington River in Connecticut. The second study was completed during the summer of 2002 along the Chattooga River which is located in South Carolina, Georgia, and North Carolina.

\section{Variables of Interest}

A list of 10 potential community benefits was generated based upon the existing literature regarding community benefits (Bruns and others 1994; Stein and others 1999). Respondents were asked to indicate on a seven-point Likert scale, how important they felt the river was in providing each benefit to local communities. We measured respondents' proximity to the resource by asking them how many miles from home they traveled to reach the river. We also asked about the frequency with which the respondent had used the river over the previous 12-months to assess their use history. Finally, data collected included respondents' socio-demographic characteristics, specifically age, education, income, race, and gender.

\section{West Branch of the Farmington River}

The West Branch of the Farmington River, located in western Connecticut, flows through a mix of rolling wooded hills, farms, and rural communities. The river is noted as one of the eastern United States' premium fly-fishing destinations; some portions of the river are also very popular spots for tubing (Passante 2001). The river was added to the Wild and Scenic River System in 1994 (Wild and Amendments 1994).
Data were collected along the West Branch of the Farmington from April to September of 2001. River users were contacted at systematically sampled access points by trained field personnel. Users were asked to complete a one-page self-administered questionnaire. At the completion of the survey, river users were asked if they would be willing to fill out a more-detailed mail-back questionnaire. Those agreeing to receive the mail-back questionnaire were sent the instrument within 10-days of contact. The questionnaires were administered according to a modified Dillman method (Dillman 2000) where up to three rounds of surveys were sent to potential respondents. A total of 483 river users were contacted, 433 (90\%) of whom completed the on-site questionnaire and agreed to receive the mail-back instrument. A total of 247 (57\%) questionnaires were returned completed. Non-response to the mailback questionnaire was checked through a comparison with data collected from on-site contacts. No significant differences were found in the gender of respondents $(P=0.764)$ or in the recreational activities they reported participating in while at the river $(P \geq 0.063)$.

\section{Chattooga River}

The Chattooga River flows through the Appalachian gorge and is one of the premier whitewater destinations in the eastern United States (Palmer 1993). The Chattooga was the first river designated by Congress since the original Wild and Scenic Rivers Act was passed in 1968 (Wild and Scenic Rivers Act 1968). A total of 56.9 miles of the river is now designated as part of the Wild and Scenic River System (Wild and Amendments 1974).

For the Chattooga River, data were collected solely through mail-back questionnaires. A sample of 2,104 river users was drawn from three distinct sources. First, lists of commercial boating customers were acquired through two outfitters located on the Chattooga. A systematic sample proportional to each outfitter's share of overall guided boating was pulled from these lists. This first sub-sample represents just guided boaters, the vast majority of whom are whitewater rafters. Second, the 2002 list of all on-site permits required of self-guided boaters was acquired from the Forest Service. This second sub-sample represents just self-guided boaters, almost all of whom are kayakers. A third sample was also procured because not all use on the Chattooga involves boating. The river corridor is also a popular hiking, fishing, and horseback riding destination. To sample these recreationists, we acquired the mailing addresses of individuals who purchased an annual Forest Service recreation pass. This subsample represents annual pass holders. The sample sizes for the guided and selfguided boater groups were selected to be roughly proportional to each group's share of overall river use based on 
the most recent Forest Service use figures available. Due to the relatively small number of annual pass holders, all of those respondents were included in the sample. A total of 982 questionnaires were sent to guided boaters, 942 to selfguided boaters, and 180 to annual pass holders. A total of 168 questionnaires were returned undelivered, making the effective sample size 1,936 . The survey was administered according to the same modified Dillman method noted for the Farmington study. A total of 841 questionnaires were returned completed for a response rate of $43.4 \%$. Nonresponse bias was not checked given three distinct populations were sampled. The effect of non-response, while expected to be low, could affect results and is a limitation of this study.

\section{Analysis}

To test the first hypothesis, that there will not be significant differences in perceived benefits across the two rivers, we utilize exploratory principal components analysis and component correlations. Exploratory principal components analysis is conducted on the perceived community benefits scale for each sample to discern distinct component structures. Visual comparisons of the component structures as well as component correlations are then employed to discern if the component structures are similar across samples. Component correlations are examined through two measures; the root mean square measure (Levine 1977; Rummel 1970) and the coefficient of congruence (Wrigley and Neuhaus 1955). The root mean square measure can range from zero (when component scores are identical in direction and magnitude) to two (when component scores are identical in magnitude but opposite in direction). The coefficient of congruence ranges from zero to one where one is equal to identical component patterns and magnitudes. We reject $\mathrm{H}_{1}$ if the root mean square is high and the coefficient of congruence is low, and fail to reject if the opposite is true.

The second, third, and fourth hypotheses, which examine the relationships between perceived community benefits and recreationists' proximity to the resource, their use history, and their socio-demographic characteristics, will be tested by first generating component scores from the exploratory principal component analyses and then regressing these onto a suite of independent variables. We examine both samples simultaneously by setting the data up in a panel format and estimating a population averaged regression equation, a specific form of generalized estimating equations (c.f., Hardin and Hilbe 2003). Two panels, one for each sample, are constructed. The panel set-up enables a more efficient analysis, when compared to estimating a regression for each sample and each component, because it uses only within-sample variation to estimate parameters and then averages the estimates over all individuals. Regression coefficients for appropriate independent variables will be utilized to test $\mathrm{H}_{2}, \mathrm{H}_{3}$, and $\mathrm{H}_{4}$.

Because this research focuses on community benefits across two qualitatively different rivers, we are also able to determine if similar relationships between socio-demographic characteristics and the perceived importance of community benefits exist across distinct resource areas. Examining differences across resource areas can help support the validity and generalizability of findings regarding the relationships between socio-demographic characteristics and perceive community benefits. The fifth and final hypothesis is tested by comparing the effect size measures between all of the independent variables and each community benefit component. We test for significant differences by estimating a generalized linear model for each sample and each community benefit component. Chisquare tests are then used to examine significant differences in effect size measures across the rivers.

\section{Results}

\section{Descriptive Statistics}

Descriptive statistics of the samples are shown in Table 1. In general, river users across both samples tended to be white, male, middle aged, and earn somewhere from forty to fifty thousand dollars a year. The samples differed significantly in their levels of educational attainment $\left(\chi^{2}\right.$ $(8)=72.98, \quad P \leq 0.001$ ), with recreationists on the Chattooga having more years of formal education. The recreationists also differed significantly in the length that they travel to get to the river $(t=11.85, P \leq 0.001)$, with river users on the Chattooga traveling further, and in their frequency of river use $(t=-9.39, P \leq 0.001)$, with river users on the West Branch of the Farmington recreating there much more frequently. These differences are expected given the drastically different development contexts that surround the rivers. The activities supported by each of the rivers are also substantially different. The West Branch of the Farmington is used primarily for fishing while the Chattooga is primarily used for whitewater rafting.

\section{Similar Perceptions of Community Benefits?}

Frequency distributions of responses to the 10-item community benefits scale are included for reference (Table 2). Across both rivers some visual trends are apparent. First, preserving undeveloped open space, aesthetic beauty, and fish and wildlife habitat were the three highest ranked benefits across both samples. Second, tourism and business development, traffic reduction and transportation 
Table 1 Descriptive statistics

\begin{tabular}{|c|c|c|c|c|c|c|}
\hline \multirow[t]{2}{*}{ Respondent characteristics } & \multicolumn{3}{|c|}{ Farmington sample $(n=247)$} & \multicolumn{3}{|c|}{ Chattooga sample $(n=841)$} \\
\hline & Percent & $M$ & $S D$ & Percent & $M$ & $S D$ \\
\hline Age & - & 47.7 & 13.8 & - & 41.0 & 11.8 \\
\hline Female & 15.5 & - & - & 25.7 & - & - \\
\hline Annual household income (mode) & - & $\$ 40,000-\$ 59,999$ & - & - & $\$ 40,000-\$ 59,999$ & - \\
\hline 4-year college degree or higher & 55.4 & - & - & 73.3 & - & - \\
\hline \multicolumn{7}{|l|}{ Race } \\
\hline White, not of Hispanic origin & 96.2 & - & - & 95.1 & - & - \\
\hline Other & 3.8 & - & - & 1.5 & - & - \\
\hline Distance from home to river (miles) & - & 58.9 & 190.5 & - & 230.5 & 280.9 \\
\hline Trips to the river during the past 12 -months & - & 26.3 & 53.7 & - & 7.2 & 15.9 \\
\hline Group size & - & 3.1 & 4.7 & - & 4.5 & 4.1 \\
\hline Length of trip in days & - & 2.8 & 2.6 & - & 3.8 & 3.0 \\
\hline \multicolumn{7}{|l|}{ Activity participation } \\
\hline Canoeing & 4.5 & - & - & 15.1 & - & - \\
\hline Kayaking & 4.9 & - & - & 38.0 & - & - \\
\hline Wildlife Observation & 17.0 & - & - & 21.3 & - & - \\
\hline Tubing & 16.6 & - & - & 1.8 & - & - \\
\hline Fishing (fly and bait) & 74.9 & - & - & 8.2 & - & - \\
\hline
\end{tabular}

Table 2 Summary of responses to questions concerning the importance of the wild and scenic river in providing community benefits

\begin{tabular}{|c|c|c|c|c|c|c|c|c|c|}
\hline \multirow[t]{2}{*}{ Potential community benefit } & \multirow{2}{*}{$\begin{array}{l}\text { Not at } \\
\text { all important } \\
\text { (1) }\end{array}$} & \multicolumn{5}{|c|}{ Response by percentages } & \multirow{2}{*}{$\begin{array}{l}\text { Extremely } \\
\text { important } \\
\text { (7) }\end{array}$} & \multirow[t]{2}{*}{$M$} & \multirow[t]{2}{*}{$S D$} \\
\hline & & (2) & (3) & (4) & (5) & (6) & & & \\
\hline \multicolumn{10}{|l|}{ West Branch of the Farmington River $(n \geq 237)$} \\
\hline Preserving undeveloped open space & 0.0 & 0.0 & 1.2 & 6.1 & 9.8 & 21.1 & 61.8 & 6.36 & 0.97 \\
\hline Aesthetic beauty & 0.0 & 0.0 & 1.2 & 6.1 & 8.6 & 22.9 & 61.2 & 6.36 & 0.96 \\
\hline Community pride & 1.7 & 2.5 & 4.2 & 13.8 & 18.3 & 22.5 & 37.1 & 5.60 & 1.47 \\
\hline Tourism and business development & 10.8 & 8.3 & 13.3 & 18.3 & 17.1 & 12.9 & 19.2 & 4.38 & 1.93 \\
\hline Traffic reduction and transportation alternatives & 10.6 & 6.8 & 11.4 & 27.4 & 13.5 & 11.8 & 18.6 & 4.36 & 1.87 \\
\hline Health and fitness & 4.6 & 2.9 & 10.1 & 18.5 & 17.7 & 21.4 & 24.8 & 5.05 & 1.68 \\
\hline Access for persons with disabilities & 2.5 & 5.8 & 8.8 & 21.7 & 18.8 & 19.6 & 22.9 & 4.99 & 1.62 \\
\hline Public recreation opportunities & 1.7 & 2.9 & 8.6 & 14.0 & 18.9 & 23.5 & 30.1 & 5.38 & 1.53 \\
\hline Public education about nature and the environment & 0.8 & 2.9 & 5.0 & 17.0 & 16.6 & 25.3 & 32.4 & 5.51 & 1.44 \\
\hline Fish and wildlife habitat & 0.0 & 0.0 & 1.2 & 4.5 & 5.3 & 14.8 & 74.2 & 6.56 & 0.88 \\
\hline \multicolumn{10}{|l|}{ Chattooga River $(n \geq 780)$} \\
\hline Preserving undeveloped open space & 0.5 & 0.1 & 1.7 & 3.3 & 7.7 & 14.0 & 72.7 & 6.50 & 0.99 \\
\hline Aesthetic beauty & 0.1 & 0.1 & 1.0 & 2.2 & 6.1 & 17.1 & 73.4 & 6.59 & 0.82 \\
\hline Community pride & 2.3 & 2.0 & 5.6 & 16.7 & 17.7 & 14.9 & 40.9 & 5.54 & 1.56 \\
\hline Tourism and business development & 10.6 & 5.7 & 11.4 & 19.6 & 17.3 & 12.8 & 22.7 & 4.56 & 1.92 \\
\hline Traffic reduction and transportation alternatives & 23.1 & 12.8 & 14.7 & 18.2 & 9.5 & 8.2 & 13.5 & 3.57 & 2.05 \\
\hline Health and fitness & 2.1 & 3.2 & 8.3 & 17.5 & 20.2 & 19.2 & 29.5 & 5.26 & 1.56 \\
\hline Access for persons with disabilities & 14.6 & 14.1 & 14.4 & 23.1 & 13.7 & 7.9 & 12.2 & 3.80 & 1.88 \\
\hline Public recreation opportunities & 3.1 & 3.3 & 5.1 & 12.0 & 15.5 & 22.0 & 39.0 & 5.56 & 1.61 \\
\hline Public education about nature and the environment & 1.7 & 3.1 & 4.6 & 14.3 & 17.2 & 19.2 & 39.9 & 5.59 & 1.53 \\
\hline Fish and wildlife habitat & 0.8 & 1.5 & 1.0 & 5.9 & 9.2 & 18.3 & 63.3 & 6.30 & 1.18 \\
\hline
\end{tabular}

Response code: $1=$ not at all important to $7=$ extremely important 
alternatives, and access for persons with disabilities were the three least important community benefits across both samples. Finally, on average all the potential community benefits were seen as at least somewhat important (average responses were all above the scale's neutral value of 3.5). Given these initial visual trends, we next turned to specific statistical approaches to discern similarities or differences across the samples.

Testing for any underlying factors in the data, Bartlett's test of sphericity $(P<0.001$ for Farmington, $P<0.001$ for Chattooga) and the Kaiser-Meyer-Olkin statistic (0.842 for Farmington, 0.787 for Chattooga) suggested that latent constructs could be present within the community benefits scale items and that factor analysis was appropriate.

Our first hypothesis stated those individuals who use the Farmington River would not perceive different community benefits than those individuals who use the Chattooga River. The data support this hypothesis as the principal component analysis yielded similar component structures across both samples (Table 3). Visual analysis suggests respondents at both study sites tended to have similar perceptions of community benefits. Specifically, individuals tended to rank the ecological and affective community benefits similarly (e.g., preserving undeveloped open space, aesthetic beauty, community pride, and fish and wildlife habitat all loaded strongly on a single component in both samples). Respondents also tended to rank the more tangible community benefits similarly (e.g., tourism and business development, traffic reduction and transportation alternative, health and fitness, and access for persons with disabilities all loaded strongly on the same component). Subsequently we classified these latent components ecological/affective community benefits and tangible community benefits.

More rigorous statistical analysis lends support for the similarity in perceived community benefits across samples. For the ecological/affective component the root mean
Table 3 Component loadings for potential community benefits

\begin{tabular}{|c|c|c|c|}
\hline Potential community benefits & Component 1 & Component 2 & $\alpha$ if deleted \\
\hline \multicolumn{4}{|l|}{ West Branch of the Farmington River $(n \geq 237)$} \\
\hline Preserving undeveloped open space & 0.873 & 0.110 & 0.82 \\
\hline Aesthetic beauty & 0.868 & 0.186 & 0.82 \\
\hline Community pride & 0.536 & 0.406 & 0.81 \\
\hline Tourism and business development & -0.003 & 0.735 & 0.82 \\
\hline Traffic reduction and transportation alternatives & 0.084 & 0.651 & 0.83 \\
\hline Health and fitness & 0.248 & 0.711 & 0.80 \\
\hline Access for persons with disabilities & 0.256 & 0.652 & 0.81 \\
\hline Public recreation opportunities & 0.297 & 0.638 & 0.81 \\
\hline Public education about nature and the environment & 0.481 & 0.580 & 0.80 \\
\hline Fish and wildlife habitat & 0.782 & 0.077 & 0.82 \\
\hline Eigenvalue & 4.26 & 1.46 & \\
\hline Percentage of variance explained & 42.6 & 14.6 & \\
\hline Cumulative variance explained & 42.6 & 57.3 & \\
\hline \multicolumn{4}{|l|}{ Total scale $\alpha=.83$} \\
\hline \multicolumn{4}{|l|}{ Chattooga River $(n \geq 780)$} \\
\hline Preserving undeveloped open space & 0.863 & 0.004 & 0.77 \\
\hline Aesthetic beauty & 0.859 & 0.018 & 0.77 \\
\hline Community pride & 0.464 & 0.415 & 0.75 \\
\hline Tourism and business development & 0.082 & 0.200 & 0.78 \\
\hline Traffic reduction and transportation alternatives & -0.059 & 0.809 & 0.77 \\
\hline Health and fitness & 0.309 & 0.613 & 0.75 \\
\hline Access for persons with disabilities & 0.056 & 0.804 & 0.76 \\
\hline Public recreation opportunities & 0.260 & 0.021 & 0.76 \\
\hline Public education about nature and the environment & 0.441 & 0.403 & 0.74 \\
\hline Fish and wildlife habitat & 0.665 & 0.192 & 0.76 \\
\hline Eigenvalue & 3.61 & 1.61 & \\
\hline Percentage of variance explained & 36.1 & 16.1 & \\
\hline Cumulative variance explained & 36.1 & 52.2 & \\
\hline Total scale $\alpha=.78$ & & & \\
\hline
\end{tabular}


square measure was 0.08 and the coefficient of congruence was 0.99; for the tangible component the root mean square was 0.23 and the coefficient of congruence was 0.88 . Both statistics suggest a high degree of similarity across samples. Based on these findings we fail to reject our first hypothesis that there will not be significant differences in perceived benefits across the two rivers.

The Effects of Resource Proximity, Use History, and Socio-Demographic Characteristics

Finding similar patterns across samples allowed us to generate component scores for both the ecological/affective community benefits component as well as the tangible community benefits component. These component scores served as the dependent variable in subsequent regressions. Results from the population averaged panel regression models are shown in Table 4.

Our second hypothesis stated that resource users' proximity to the river will not be significantly related to their perceptions of how the resource benefits local communities. Support for this hypothesis was mixed. A respondents' proximity to the resource was significantly related to their perceptions of the river providing ecological and affective community benefits. The coefficient for this variable $(\beta=-0.0003, Z$-score $=-3.040)$ indicates a significant negative relationship, implying that as distance from the resource increases, perceptions of the river providing ecological or affective community benefits declines. However, a similar negative relationship was not found between respondents' resource proximity and their perceptions of tangible community benefits $(\beta=0.0001$, Z-score $=1.210$ ).

For our third hypothesis, regarding the relationship between resource use history and perceptions of community benefits, the results were again mixed. The frequency with which a respondent visits the river was significantly and negatively related to perceptions of tangible community benefits $(\beta=-0.0008, Z$-score $=-4.000)$. This finding implies the more frequently an individual has visited the river, the more likely they are to perceive the river as providing tangible benefits to local communities. The relationship between frequency of use and perceptions of ecological/affective community benefits was not significant however $(\beta=0.0025, Z$-score $=1.820)$. Based upon the mixed findings for both the resource proximity and the use history variable, we reject $\mathrm{H}_{2}$ and $\mathrm{H}_{3}$ which proposed that no significant relationships existed.

Our fourth hypothesis stated there will be no significant relationship between perceptions of community benefits and recreationists' socio-demographic characteristics. Gender was significantly related to both the importance of ecological/affective community benefits $(\beta=0.0898$, $Z$-score $=1.900)$ and tangible community benefits $(\beta=$ $0.3694, Z$-score $=6.460)$. Female river users rated both sets of benefits significantly higher than did male users. Also, age was significantly and positively related to the perceived importance of tangible community benefits $(\beta=0.0038, Z$-score $=8.120)$. Finally, river users with higher levels of education are more likely to believe the rivers produce ecological or affective benefits to local communities $(\beta=0.0772, Z$-score $=11.460)$. Given the presence of several significant differences in the perceived importance of community benefits based upon individuals' socio-demographic characteristics, we reject our fourth hypothesis.

\section{Different Socio-Demographic Effects Between Samples?}

The final analysis compared the effect size measures across each of the resource areas as a check of the reliability of

Table 4 Population averaged panel regression of perceived community benefits on respondent characteristics

\begin{tabular}{|c|c|c|c|c|c|c|}
\hline \multirow[t]{4}{*}{ Independent variables } & \multicolumn{6}{|c|}{ Dependent variables } \\
\hline & \multicolumn{3}{|c|}{ Ecological/affective } & \multicolumn{3}{|l|}{ Tangible } \\
\hline & \multicolumn{3}{|c|}{ Community benefits component } & \multicolumn{3}{|c|}{ Community benefits component } \\
\hline & $\beta$ & Semi-robust SE & Z-score(sig.) & $\beta$ & Semi-robust SE & Z-score(sig.) \\
\hline Miles & -0.0003 & 0.0001 & $-3.040 * *$ & 0.0001 & 0.0001 & 1.210 \\
\hline Trips within the past 12 -months & 0.0025 & 0.0014 & 1.820 & -0.0008 & 0.0002 & $-4.000 * * *$ \\
\hline Gender & 0.0898 & 0.0473 & $1.900^{*}$ & 0.3694 & 0.0572 & $6.460 * * *$ \\
\hline Age & 0.0013 & 0.0010 & 1.320 & 0.0038 & 0.0005 & $8.120 * * *$ \\
\hline Education & 0.0772 & 0.0067 & $11.460 * * *$ & -0.0364 & 0.0274 & -1.330 \\
\hline Income & -0.0055 & 0.0140 & -0.390 & -0.0046 & 0.0103 & -0.440 \\
\hline Race & 0.0630 & 0.0350 & 1.800 & 0.0028 & 0.0421 & 0.070 \\
\hline
\end{tabular}

*** $P \leq 0.001, * * P \leq 0.01, * P \leq 0.05$ 
Table 5 Comparison of regression coefficients between the west branch of the farmington river and the chattooga river

\begin{tabular}{|c|c|c|c|c|}
\hline \multirow[t]{3}{*}{ Test coefficient } & \multicolumn{2}{|c|}{ Ecological/affective } & \multicolumn{2}{|c|}{ Tangible } \\
\hline & \multicolumn{2}{|c|}{ Community benefits regressions } & \multicolumn{2}{|c|}{ Community benefits regressions } \\
\hline & $\chi^{2}$ & $P$ & $\chi^{2}$ & $P$ \\
\hline Miles & 3.740 & 0.055 & 0.480 & 0.488 \\
\hline Trips within the past 12 -months & 5.630 & 0.018 & 0.070 & 0.795 \\
\hline Gender & 0.230 & 0.631 & 0.960 & 0.327 \\
\hline Age & 0.100 & 0.754 & 0.020 & 0.880 \\
\hline Education & 0.000 & 0.956 & 1.780 & 0.182 \\
\hline Income & 2.360 & 0.125 & 0.540 & 0.461 \\
\hline Race & 0.200 & 0.652 & 0.800 & 0.373 \\
\hline
\end{tabular}

our estimates presented in Table 4. The comparative statistics are shown in Table 5. Only one coefficient, trips within the past 12-months, differed significantly across the resource areas, and this difference was only noticed for the ecological/affective regressions. Notably, this variable was not a significant predictor of individuals' perceived importance of ecological/affective community benefits (Table 4), which implies that all the coefficients estimated for Table 4 are not statistically different for both samples. Based on this finding, we fail to reject $\mathrm{H}_{5}$.

\section{Discussion}

In the past, economic benefits have been the focus of most empirical studies and management actions as they were the easiest to quantify. More recently however, recreation scholars and managers are realizing that for agencies to develop successful collaborative partnerships with local communities, the importance of other benefits such as affective and emotional connections to the resource as well as ecological benefits must be more explicitly stated and managed for (Williams and Stewart 1998; Glover and others 2008). Previous research aimed at understanding these community benefits has yielded several trends. Specifically, perceived benefits tend to revolve around communities' environmental quality, their quality of life, and almost always, their economy. These benefits are essentially expressions of how individuals believe recreation resources add value to their lives (Anderson and others 2008a).

Our analysis shows distinct patterns in the perception of these benefits, even across two distinct resources located in different parts of the United States. Specifically, individuals tended to see the resource as important because either it added very tangible benefits to the community or because it enabled the community to retain its ecological integrity while also fostering intangible benefits such as aesthetic beauty and community pride. This pattern of perceived benefits is notable on several counts. First, the previous literature acknowledges that individuals' perceptions of the benefits produced from recreation resources are diverse (Stein and others 1999; Anderson and others 2008a). However, research into how those perceptions vary, both within specific populations (e.g., local communities, user groups) and across resource areas, have largely gone unexplored. These findings suggest that distinct trends and patterns in the perceived importance of wildland recreation resources could be present across a variety of recreation settings. Second, if management is to understand how to capture the positive benefits and avoid negative impacts of their management actions, they need to be aware of how individuals believe the resource benefits their community; more importantly they need to be aware of the composition and patterns in those perceptions. Our findings shed light onto the varied perceptions of community benefits produced by the Chattooga and the West Branch of the Farmington River. The findings raise the question of whether similar perceptions exist at other preserved rivers or other wildland recreation areas as well, and should be explored further in future research.

In a similar vein, recreation resource managers serve not only local communities but also recreationists who travel from outside their immediate geographic areas. As such, they need to be aware of how perceptions can vary relative to resource proximity. Our findings show that more proximate river users tended to perceive the ecological and affective community benefits as more important than less proximate users. A possible explanation for this finding can be drawn from existing literature concerning resource proximity and affective connections to natural landscapes. Explicitly, several studies have found individuals more proximate to resource areas have a greater affective connection to the resource, are more likely to perceive environmental changes, and are more likely to support management actions geared toward resource conservation 
(Drenthen 2009; Larson and Santelmann 2007). The data from both the West Branch of the Farmington and the Chattooga River align with the findings from these previous studies. Resource proximity appears to have a consistent and significant impact on individuals' perceptions of managed resource areas, especially toward the affective feelings and ecological benefits they produce.

The relationship between resource proximity and perceived community benefits did not extend to the set of benefits we defined as tangible however. Both proximate and non-proximate resource users held similar perceptions of how the rivers benefitted local communities economically, through encouraging increased tourism and business development for example, and socially, through providing areas that improve the local population's health and fitness levels. The disparate findings for the relationship between resource proximity and both sets of identified community benefits suggests management actions that might impact regional ecosystems are more likely to be perceived by local resource users relative to less-proximate resource users. The same however, cannot be said for management actions that alter the tangible benefits, such as educational opportunities or increased economic revenues, which accrue to local communities. As a result, management efforts could be targeted to specific populations more likely to perceive the impacts which they may have.

Our third hypothesis explicitly explored whether perceptions of community benefits varied relative to individuals' prior recreation experience on the rivers. Theoretically, the paucity of research on the relationship between resource use history and setting perceptions did not suggest perceived community benefits would vary relative to a recreationists' prior behavior. The data from both the West Branch of the Farmington and the Chattooga support this assumption. It appears that individuals' perceptions of how managed resource areas impact local communities has more to do with where they live and their individual socio-demographic characteristics than with their recreation behavior.

Contrary to our third hypothesis, we rejected the proposition that resource users' perceptions of community benefits were not related to their socio-demographic characteristics. The data revealed several significant variations that could impact the actions of resource management. First, regarding gender, the results show women perceive the importance of both sets of community benefits significantly more than men. One possible explanation follows the argument that traditional gender socialization, cultural norms, and women's historical role as caregivers and nurtures, lead them placing greater value on social health and welfare benefits generated through higher quality environments (Hunter and others 2004; Zelezny and others 2000). Four of the six tangible community benefits refer to items that are typically conceptualized within the sphere of general social welfare. Health and fitness, access for persons with disabilities, public recreation opportunities, and public education are all benefits involving the community's well-being, and in particular the well-being of less fortunate individuals and children. In short, gendered differences in perceptions of community benefits may be a reflection of divergent beliefs and perceptions about the environment and the need to protect the benefits that accrue to society through resource management and conservation efforts.

While gender was the only socio-demographic variable significantly related to perceptions of both ecological/ affective community benefits as well as tangible community benefits, the age and education variables also exhibited a significant relationship to at least one set of community benefits. The data show that older individuals were more likely to perceive the tangible community benefits as important. However, no significant relationships were found between the ecological/affective set of benefits and respondents' socio-demographic characteristics. The mixed support across both sets of community benefits suggests a weak connection to resource users' age.

Counter to the inconsistent relationship between age and perceptions of benefits accrued by local communities, a strong and regular relationship is often associated between individuals' education level and their perceptions of certain community benefits. Specifically, the importance of ecological preservation tends to correlate highly with education levels (e.g., Stem and others 2004; Gelissen 2007) and our data from users of both Wild and Scenic Rivers concurs with this general pattern. These findings are logical and indicate more educated resource users will be more sensitive to potential management actions that will impact the ecosystem services provided by the resource.

Finally, the validity and generalizability of the findings presented in this research are bolstered through the use of data from two distinctly different Wild and Scenic Rivers, each of which is located in a unique geographic setting and offering specific, and different, recreational opportunities to visitors. Through the analysis of our first hypothesis, the data reveal similar patterns of perceived community benefits across the study areas despite differences in the settings. Furthermore, our fifth hypothesis examined the relationship between recreationists' socio-demographic characteristics and each of the two dimensions of perceived community benefits (ecological/affective and tangible). Finding no significant differences in the effects of users' socio-demographic characteristics on perceived community benefits across the two study areas is particularly important for resource managers. Through an understanding of which users are most likely to believe certain benefits are important to them and local communities near the areas 
they manage, resource planners and managers are more prepared to preemptively understand how specific management actions might be perceived by those users. As a result, preemptive management actions, such as engaging specific user groups, ideally those most likely to be impacted by, or perceive the impacts of specific management actions, can be employed in an effort to develop the stronger, collaborative relationships needed for successful resource management.

\section{Limitations}

The research presented here has generated a set of generalizable findings about how recreationists perceive the importance of community benefits produced by Wild and Scenic Rivers. These findings were informed by data collected from recreationists at two distinct rivers. While using data from two distinct sources can improve the reliability of the findings, it also introduces a unique limitation. Specifically, data were collected in two different manners at each of the study areas, on-site contacts followed up by mail-questionnaires along the West Branch of the Farmington and just mail-questionnaires along the Chattooga. As a result, one sampling procedure may be capturing more local visitors or more frequent recreationists than the other sampling procedure.

Another limitation of the methodology employed in this study is the collection of data only from individuals who use the rivers for recreational purposes. The perceptions and needs of non-recreationists can and often does play a large role in resource management. Future research efforts need to examine the perceived importance of community benefits from the perspective of both non-resource users who live in local communities as well as recreationists. A more inclusive approach could give resource managers and social scientists a better insight into variations in the perceived importance of different community benefits.

A final limitation of this study stems from its applied management focus and grounding in OFM. As noted in the overview of OFM literature, the fundamental principle guiding the framework is that management should focus on understanding how to maximize the desired benefits accrued to resource users and the communities located in and around managed resource areas while simultaneously trying to minimize undesired effects (Driver 2008b). As an unfortunate byproduct of this principle, the psychometric scales developed to ascertain individual and community benefits only include positive benefit statement items. Since the development of benefits based frameworks in the late 1970s, scale development has almost exclusively been limited to positively phrased benefit statement items. The assumption being that the primary focus of management actions should be on maximizing these desired benefits.
Unfortunately however, a more complete social scientific understanding of the relationships between resource users, local communities, and managed resource areas could be developed with data collected on both desired benefits and potential negative outcomes. An underlying objective of the research presented in this paper was to extend OFM from explicitly individual benefits to broader community benefits. The OFM literature could also benefit greatly through the development and refinement of more balanced, diametric, and theoretically informed instruments. Given this, our research presented above is limited by its focus on perceived community benefits.

\section{Conclusion}

In summary, the analysis of perceived community benefits produced by the West Branch of the Farmington and the Chattooga Rivers illustrate that local communities undoubtedly have a complex relationship with wildland recreation areas and their management. More importantly, the analysis revealed that while this relationship is complex, and while the function and context of resource areas can differ dramatically, the users of those areas tend to perceive community benefits in very similar ways. Whether through ecological/affective benefits or more tangible benefits, similar patterns emerged from our data on visitors' perceptions. For resource managers, a clearer understanding of these benefits can aid in the development of successful and sustainable resource management practices and policies. Perceived community benefits, after all, are relatively distinct management outcomes that resource users would like to see provided for. Without understanding these desired management outcomes, resource management agencies cannot understand how their actions should be focused so the positive benefits desired by resource users can be realized. For the same reason, managing agencies need to be aware of how these perceptions vary among resource users. As in the case of the Farmington and Chattooga Rivers, individuals' socio-demographic characteristics and their relationship with the resource could significantly affect their perceptions of how the resource and its management affect surrounding communities.

Acknowledgments This research was funded by the Rivers, Trails, and Conservation Assistance Program of the National Park Service.

\section{References}

Allen LR (1991) Benefits of leisure service to community satisfaction. In: Driver BL, Brown PJ, Peterson GL (eds) Benefits of leisure. Venture, State College, PA, pp 331-350 
Anderson DH, Davenport MA, Leahy JE, Stein TV (2008a) OFM and local community benefits. In: Driver BL (ed) Managing to optimize the beneficial outcomes of recreation. Venture, State College, PA, pp 311-334

Anderson DH, Wilhem Stanis SA, Schneider IE, Leahy JE (2008b) Proximate and distant visitors: differences in importance ratings of beneficial experiences. Journal of Park and Recreation Administration 26(4):47-65

Bruns D, Driver BL, Lee ME, Anderson DH, Brown PJ (1994) Pilot test for implementing benefits-based management. In: Paper presented at the fifth international symposium on society and resource management, June 7-10, Fort Collins, CO

Campbell A (1981) The sense of well-being in America: recent patterns and trends. McGraw Hill, New York

Cramer LA, Kennedy JJ, Krannich RS, Quigley TM (1993) Changing Forest Service values and their implications for land management decisions affecting resource-dependent communities. Rural Sociology 58(3):475-491

Daniels SE, Cheng AS (2004) Collaborative resource management. In: Manfredo MJ, Vaske JJ, Bruyere BL, Field DR, Brown PJ (eds) Society and natural resources: a summary of knowledge. Litho Press, Jefferson, MO, pp 127-136

Davenport MA, Anderson DH (2005) Getting from sense of place to place-based management: an interpretive investigation of place meanings and perceptions of landscape change. Society \& Natural Resources 18(7):625-641

Dillman DA (2000) Mail and internet surveys: the tailored design method, 2nd edn. Wiley, New York

Drenthen MAM (2009) Ecological restoration and place attachment: emplacing non-places? Environmental Values 18:285-312

Driver BL (2008a) What is outcomes-focused management? In: Driver BL (ed) Managing to optimize the beneficial outcomes of recreation. Venture, State College, PA, pp 19-38

Driver BL (2008b) Why outcomes-focused management is needed. In: Driver BL (ed) Managing to optimize the beneficial outcomes of recreation. Venture, State College, PA, pp 1-18

Driver BL, Brown PJ, Peterson GL (eds) (1991) Benefits of leisure. Venture, State College, PA

Dunlap RE, van Liere KD, Mertig AG, Jones RE (2000) Measuring endorsement of the new ecological paradigm: a revised NEP scale. Journal of Social Issues 56(3):425-442

Eder J (2005) Coastal resource management and social differences in Philippine fishing communities. Human Ecology: An Interdisciplinary Journal 33(2):147-169

Federal Land Policy and Management Act (1976) Pub. L. No. 94-579

Federal Water Project Recreation Act (1965) Pub. L. No. 89-72

Gelissen J (2007) Explaining popular support for environmental protection: a multilevel analysis of 50 nations. Environment and Behavior 39(3):392-415

Glover TD, Stewart WP, Gladdys K (2008) Social ethics of landscape change: toward community-based land-use planning. Qualitative Inquiry 14(3):384-401

Graefe A, Moore RL (1992) Monitoring the visitor experience at Buck Island Reef National Monument. In: Proceedings of the 1991 northeastern recreation research symposium, USDA Forest Service General Technical Report NE-160, pp 55-58

Hammitt WE, Backlund EA, Bixler RD (2004) Experience use history, place bonding and resource substitution of trout anglers during recreation engagements. Journal of Leisure Research 36(3):356-378

Hardin JW, Hilbe JM (2003) Generalized estimating equations. Chapman \& Hall/CRC, Boca Raton, FL

Harper JL, Neider D, Godbey G, Lamont D (1997) The use and benefits of local government parks recreation services: a Canadian perspective. Health, Leisure, and Human Dimensions
Research Institute, University of Manitoba, Winnipeg, Manitoba, Canada

Hjerpe EE, Kim Y (2007) Regional economic impacts of Grand Canyon river runners. Journal of Environmental Management 85(1):137-149

Hunter LM, Hatch A, Johnson A (2004) Cross-national gender variation in environmental behaviors. Social Science Quarterly 85:677-694

Keith J, Jakus P, Larsen J, Burr S, Reiter D, Zeitlin J (2008) Impacts of wild and scenic river designation: a report for the Utah Governor's public lands office. Department of Economics Utah State University, Logan UT

Larson KL, Santelmann MV (2007) An analysis of the relationship between residents' proximity to water and attitudes about resource protection. Professional Geographer 59(3):316-333

Leahy JE (2005) US Army Corps of Engineers and Kaskaskia River Watershed community relationships: social capital, trust, and benefits. Unpublished doctoral dissertation, University of Minnesota

Lemelin RH (2009) Doubting Thomases and the cougar: the perceptions of puma management in Northern Ontario, Canada. Sociologia Ruralis 49(1):56-69

Levine MS (1977) Canonical analysis and factor comparison. Quantitative Applications in the Social Sciences. Sage, Newbury Park, CA

Marans R, Mohai P (1991) Leisure resources, recreation activity, and the quality of life. In: Driver BL, Brown P, Peterson G (eds) Benefits of leisure. Venture, State College, PA, pp 351-363

Moore RL, Driver BL (2005) Evolution of science-based management of outdoor recreation resources. In: Moore RL, Driver BL (eds) Introduction to outdoor recreation: providing and managing natural resource based opportunities. Venture, State College, PA, pp 155-184

Moore RL, Siderelis C (2003a) Use and economic importance of the Wild and Scenic Chattooga River. American Rivers, Inc., Washington, DC

Moore RL, Siderelis C (2003b) Use and economic importance of the West Branch of the Farmington River. American Rivers, Inc., Washington, DC

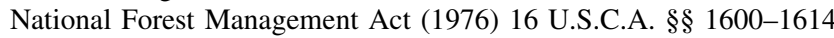

National Park Service Organic Act (1916) 16 U.S.C. $\S \S 1-4$

National Wildlife Refuge System Improvement Act (1997) Pub. L. No. 105-57

Palmer T (1993) The wild and scenic rivers of America. Island Press, Washington, DC

Passante J (2001) Farmington river hatches. Fly Fisherman 22(5): $48-51,60-62$

Perez-Verdin G, Lee M, Chavez D (2004) Outdoor recreation in a protected area in Southern Durango, Mexico: Analysis of local residents' perceptions. Society and Natural Resources 17:897910

Rummel RJ (1970) Applied factor analysis, 2nd edn. Northwestern University Press, Evanston IL

Stein TV, Anderson DH (2002) Combining benefits-based management with ecosystem management for landscape planning: Leech Lake watershed, Minnesota. Landscape and Urban Planning 60:151-161

Stein TV, Lee ME (1995) Managing recreation resources for positive outcomes: an application of benefits-based management. Journal of Park and Recreation Administration 13:52-70

Stein TV, Anderson DH, Thompson D (1999) Identifying and managing for community benefits in Minnesota state parks. Journal of Park and Recreation Administration 17(4):1-19

Stem CJ, Lassoie JP, Lee DR, Deshler DD, Schelhas JW (2004) Community participation in ecotourism benefits: The link to 
conservation practices and perspectives. Society and Natural Resources 16:387-413

White DD, Virden RJ, van Riper CJ (2008) Effects of place identity, place dependence, and experience-use history on perceptions of recreation impacts in a natural setting. Environmental Management 42(4):647-657

Wild and Scenic Rivers Act (1968) Public Law 90-541

Wild and Scenic Rivers Act-Amendments (1974) Public Law 93-279
Wild and Scenic Rivers Act-Amendments (1994) Public Law 103-242

Williams DR, Stewart SI (1998) Sense of place: An elusive concept that is finding a home in ecosystem management. J For 96:18-23

Wrigley C, Neuhaus J (1955) The matching of two sets of factors. Am Psychol 10:418-419

Zelezny LC, Chua P-P, Aldrich C (2000) Elaborating on gender differences in environmentalism. Journal of Social Issues 56: 443-457 